\title{
Comparison of Linear Measurements and Analyses taken from Plaster Models and Three-dimensional Images
}

\author{
${ }^{1}$ Betina Grehs Porto, ${ }^{2}$ Thiago Soares Porto, ${ }^{3}$ Monica Barros Silva, ${ }^{4}$ Renésio Armindo Grehs, ${ }^{5}$ Ary dos Santos Pinto \\ ${ }^{6}$ Shilpa H Bhandi, ${ }^{7}$ Mateus Rodrigues Tonetto, ${ }^{8}$ Matheus Coelho Bandéca, ${ }^{9}$ Lourdes Aparecida Martins dos Santos-Pinto
}

\begin{abstract}
Digital models are an alternative for carrying out analyses and devising treatment plans in orthodontics. The objective of this study was to evaluate the accuracy and the reproducibility of measurements of tooth sizes, interdental distances and analyses of occlusion using plaster models and their digital images. Thirty pairs of plaster models were chosen at random, and the digital images of each plaster model were obtained using a laser scanner (3Shape R-700, 3Shape A/S). With the plaster models, the measurements were taken using a caliper (Mitutoyo Digimatic ${ }^{\circledR}$, Mitutoyo (UK) Ltd) and the MicroScribe (MS) 3DX (Immersion, San Jose, Calif). For the digital images, the measurement tools used were those from the O3d software (Widialabs, Brazil). The data obtained were compared statistically using the Dahlberg formula, analysis of variance and the Tukey test $(p<0.05)$. The majority of the measurements, obtained using the caliper and O3d were identical, and both were significantly different from those obtained using the MS. Intra-examiner agreement was lowest when using the MS. The results demonstrated that the accuracy and reproducibility of the tooth measurements and analyses from the plaster models using the caliper and from the digital models using $\mathrm{O} 3 \mathrm{~d}$ software were identical.
\end{abstract}

Keywords: Digital models, Study models, Orthodontics.

\footnotetext{
${ }^{1}$ Orthodontics Doctorate Student, ${ }^{2,4-9}$ Professor

${ }^{1,5,9}$ Department of Pediatric Dentistry, School of Dentistry at Araraquara, UNESP - São Paulo State University, AraraquaraSP, Brazil

${ }^{2}$ Department of Restorative Dentistry, School of Dentistry at Araraquara, UNESP - São Paulo State University, AraraquaraSP, Brazil

${ }^{3,8}$ Department of Post-Graduate Program in Dentistry, CEUMA University, Sao Luis-Maranhão, Brazil
}

${ }^{4}$ Department of Orthodontics, Federal University of Santa Maria, UFSM, Rua Marechal Floriano Peixoto, Santa Maria Rio Grande do Sul, Brazil

${ }^{6}$ Department of Conservative Dentistry and Endodontics, MS Ramaiah Dental College and Hospital, Bengaluru, Karnataka India

${ }^{7}$ Department of Post-Graduate Program in Integrated Dental Sciences, University of Cuiabá, Mato Grosso, Cuiabá

Corresponding Author: Betina Grehs Porto, Orthodontics Doctorate Student, Department of Pediatric Dentistry, School of Dentistry, Araraquara, Rua Humaita 1680, Araraquara-SP Brazil-14801-903, e-mail: betinagrehs@hotmail.com
How to cite this article: Porto BG, Porto TS, Silva MB, Grehs RA, dos Santos Pinto A, Bhandi SH, Tonetto MR, Bandéca MC, dos Santos-Pinto LAM. Comparison of Linear Measurements and Analyses taken from Plaster Models and Three-dimensional Images. J Contemp Dent Pract 2014;15(6):681-687.

Source of support: Nil

Conflict of interest: None declared

\section{INTRODUCTION}

The plaster models used in orthodontics are the basic tools for patient diagnosis. The information obtained from the analysis of models is of fundamental importance for the correct planning and execution of orthodontic treatment.

Traditionally, the size of the teeth and the distances for the analysis of occlusions in plaster models have been obtained using dry-tip compasses or a digital caliper. Recently, the MicroScribe (MS) 3DX (Immersion, San Jose, Calif.), associated with TIGARO software, has been considered an accurate and reliable instrument for obtaining measurements using plaster models capable of being used both in clinical practice and in research. ${ }^{4}$

Digital models are gradually becoming more prevalent in orthodontics clinics, providing an alternative to the routinely used plaster models. ${ }^{13,15,16,18}$ Among the advantages of digital images over plaster models are their facility of storage and the reduced risk of physical damage or loss. Digital models also enable the exchange of information with colleagues or other specialists involved in treatment and even with the patient himself. ${ }^{1-3,10,11,13-15,20,22}$

Digital model technology makes it possible to obtain a virtual image of the patient's dental arch, from an impression or from an existing plaster model of the patient. This image can be sent to an orthodontist while remaining on the company's website for download and for reference during measurement and analysis. ${ }^{1-3,10-16,20}$ Recent studies involving this new technology have shown that the measurements of tooth size, arch widths and overjets and overbites in digital models are valid and can be reproduced. ${ }^{14,21}$

The objective of this study was to compare the accuracy, precision and reproducibility of dental measurements obtained from plaster models using a digital caliper (Mitutoyo Digimatic $^{\circledR}$, Mitutoyo (UK) Ltd) and MS 3DX 
(Immersion, San Jose, Calif) and from three-dimensional images produced by the O3d system (Widialabs, Brazil) to consider the possible advantages and disadvantages of this new technology in orthodontics.

\section{MATERIALS AND METHODS}

For the present study, we selected 30 pairs of plaster models from the initial orthodontic documentation of the Postgraduate Orthodontics Clinic at the Araraquara School of Dentistry of UNESP/SP. These documents had been completed according to the same standards and by the same professional.

The criteria for including the plaster models in the study were:

- The presence of incisors, canines, premolars and first permanent molars

- Normal morphology present in all the teeth

- The absence of irregularities in the plaster deriving from carious lesions and restorations, which might affect the mesiodistal or buccolingual diameter of the dental crown

- The absence of previous orthodontic treatment.

The original models were duplicated to avoid the risk of damage to the patients' permanent records. The impressions were carried out by the same professional with the Morelli no. 7 impression tray with alginate (Jeltrate, Dentsply). The models were made from special stone-type gypsum (Durone V, Dentsply) and were spatulated under vacuum and vibration to decrease the presence of bubbles. After the setting of the plaster, the dry models were inserted in an articulator for the preparation of the base.

The points of reference ( 28 in each arch) were identified in the models with a number 3 pencil, to help in the positioning of the measuring instruments (Figs 1 and 2). The measurements were taken two times by the same examiner, with an interval of 1 week between measurements.

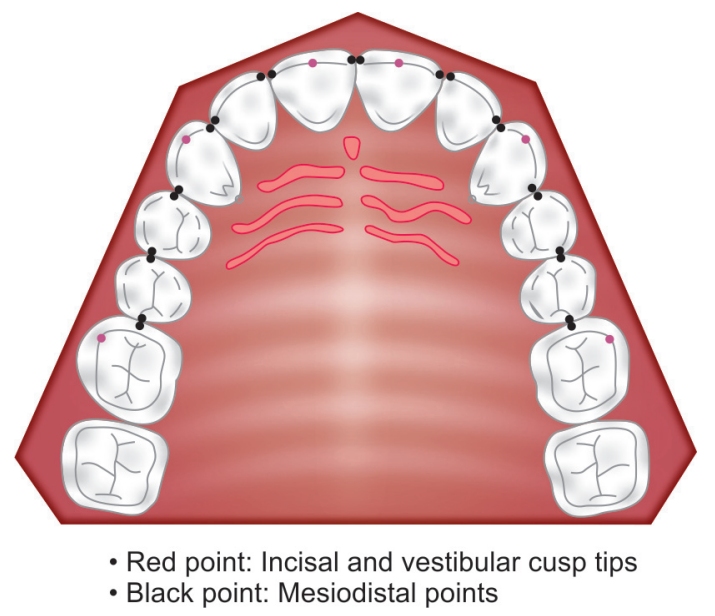

Fig. 1: Points marked on the upper model to be measured and digitalized
The plaster models were measured manually with a digital caliper (Mitutoyo Digimatic ${ }^{\circledR}$, Mitutoyo (UK) Ltd) (Paq), with a precision of $0.01 \mathrm{~mm}$, and with the MS 3-DX 3D Digitizer (Immersion, San Jose, Calif.) positioned on a flat surface.

The image of each plaster model was obtained using a non-destructive laser scanning technique, with the reading being taken by means of a laser surface scan (3Shape R-700, 3Shape A/S), without contact with the model (Fig. 3) and with a precision of 0.005 " and 400 dots per inch. The measurements and analyses (Figs 4 and 5) were carried out using tools from the O3d software application (Widialabs, Brazil).

An equilateral triangle with sides of $1.0 \mathrm{~cm}$, made from acrylic, was positioned at the rear of the upper model (Fig. 6) and used as a gold standard, proving that there was no enlargement of the image of the plaster model when it was digitalized by the O3d system.

The following linear measurements were obtained:

- Tooth size: The mesiodistal diameter of the first molars, premolars, canines and incisors of both arches

- Horizontal overjet (projection): The measurement taken from the extremity of the edge of the lower incisor to the rearmost edge of the upper incisor, in the horizontal direction, parallel to the occlusal plane

- Vertical overbite: The measurement taken considering the distance between the point of contact of the cusp of the lower central incisor to a horizontal of the distance between the upper central incisor and the lower incisor, in the vertical direction, in parallel to the occlusal plane

- Intercanine distance: The distance between the points of the cusps of the permanent canines

- Intermolar distance: The distance between the tips of the mesiovestibular cusps of the first permanent molars. The following analyses were carried out:

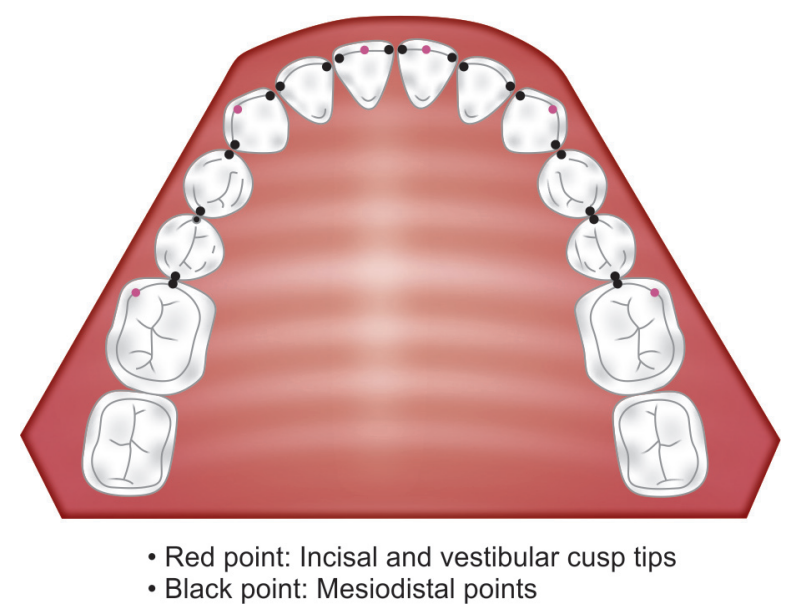

Fig. 2: Points marked on the lower model to be measured and digitalized 


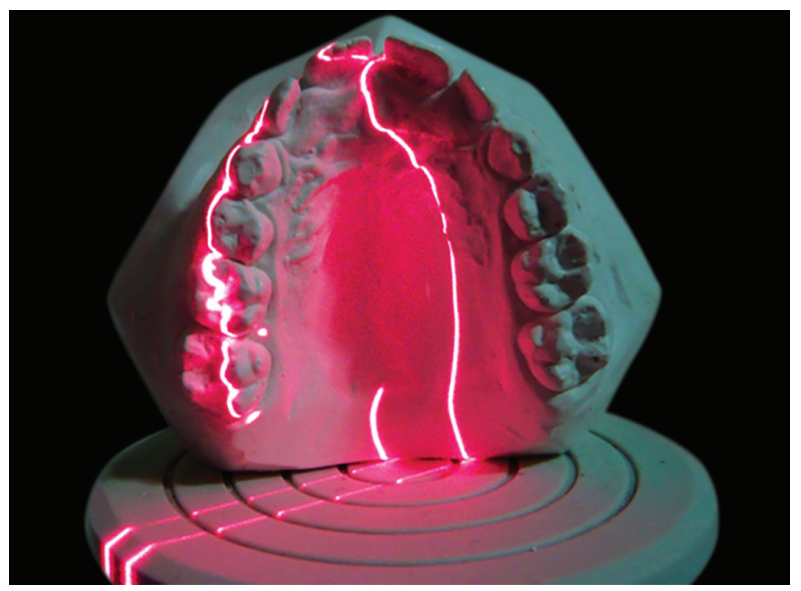

Fig. 3: Laser scanning of the plaster model

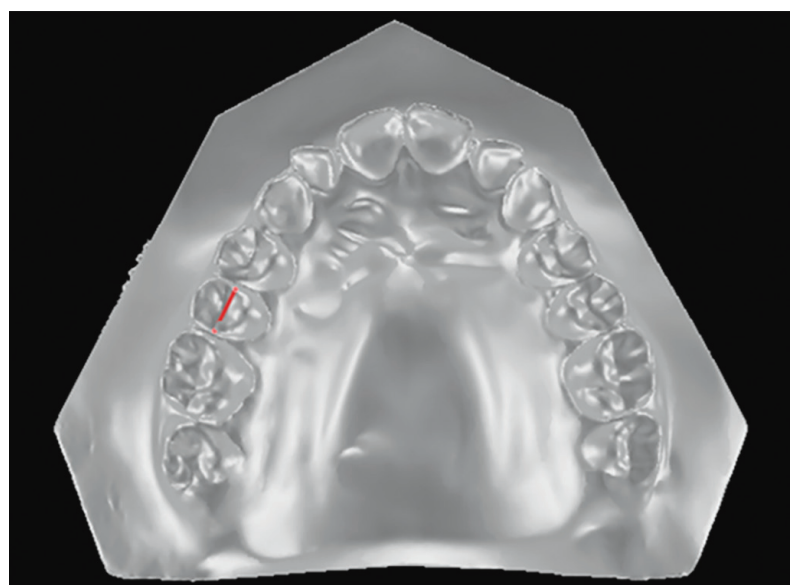

Fig. 5: Example of the measurement of the tooth size of the upper second premolar with the digital model

- Bolton analysis: Calculation of the discrepancy of tooth size and

- Little's irregularity index: ${ }^{8}$ An index that quantitatively evaluates the individual's mandibular anterior crowding, with the following values:

0 , perfect alignment; 1-3, minimum irregularity; 4-6, moderate irregularity; 7-9, severe irregularity and 10, very severe irregularity.

The evaluation of possible alterations in the measurements and in the distances obtained by the three measuring instruments was undertaken using analysis of variance (ANOVA) and the complementary Tukey test, with a significance of 0.05 .

The intra-examiner variability was determined by calculating the method error with Dahlberg's formula, using the difference between the first and second measurements in the 30 pairs of models. ${ }^{6}$ Student's t-test was used on paired samples, with the aim of detecting the presence of systematic error.

For the calibration of the methods of measurement, ${ }^{10}$ pairs of models, selected at random by means of a simple casual sampling, were measured by the same examiner with the three measuring instruments two times, with

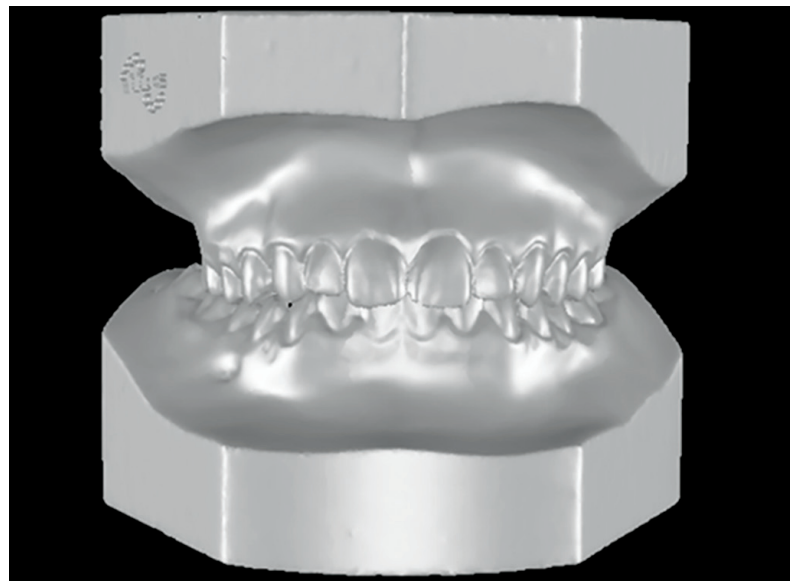

Fig. 4: Example of the front view of the digital model in the O3d System

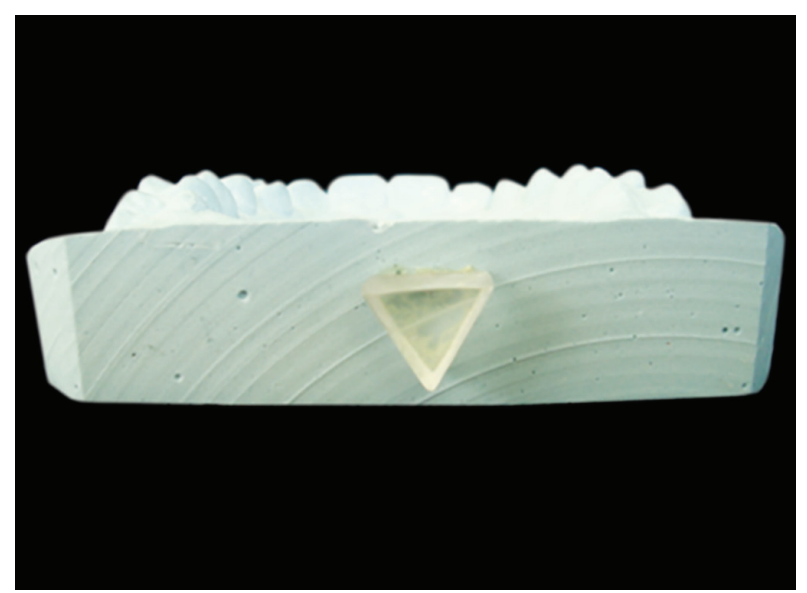

Fig. 6: Equilateral triangle - the gold standard for determining the enlargement factors of the image

an interval of a week between measurements. The reliability of the measuring process of the variables was evaluated by the intraclass correlation coefficient (ICC) for the caliper (ICC $=0.98)$, for the MS $($ ICC $=0.99)$ and for the O3d System (ICC $=0.99$ ).

\section{RESULTS}

The means of the two series of measurements and the results of the statistical analyses obtained for the groups of teeth are described in Tables 1 and 2 and, for the other measurements and analyses, in Tables 3 and 4 .

The analysis of the size of the teeth was undertaken in accordance with the different groups of teeth: molars, premolars, canines and incisors. The random error demonstrated by the Dalhberg formula occurred in the molars and the canines when the measuring instrument used was the MS, with values greater than 0.10 (Table 1). In the evaluation of the systematic error (p), a significant difference occurred in the measurements undertaken with the caliper for the premolars, canines and incisors. The correlation ( $\mathrm{r}$ ) between the first and the second measurements was excellent, and the difference observed was in 
Table 1: Mean values, difference, standard deviation, standard error of difference, random error (Dahlberg), systematic error ( $p$ ) in $\mathrm{mm}$, correlation $(r)$ and coefficient of precision (CP) for the mesiodistal diameter of molars, premolars, canines and incisors

\begin{tabular}{lllllllllll}
\hline Teeth group & Method & Mean 1 & Mean 2 & Difference & $D P$ & $E P$ & Dahlberg & $p$ & $r$ & $C P$ \\
\hline Molars & O3D & 9.82 & 9.81 & 0.01 & 0.06 & 0.01 & 0.04 & 0.647 & 0.99 & 0.994 \\
& Paq & 9.84 & 9.82 & 0.02 & 0.08 & 0.01 & 0.06 & 0.169 & 0.99 & 0.989 \\
\multirow{5}{*}{ Premol } & MS & 10.19 & 10.26 & -0.07 & 0.19 & 0.03 & 0.14 & 0.065 & 0.96 & 0.957 \\
& O3D & 6.43 & 6.43 & 0.00 & 0.07 & 0.01 & 0.05 & 0.912 & 0.98 & 0.979 \\
& Paq & 6.54 & 6.45 & 0.09 & 0.12 & 0.02 & 0.10 & $0.000^{*}$ & 0.95 & 0.955 \\
Canines & MS & 6.78 & 6.80 & -0.02 & 0.13 & 0.02 & 0.09 & 0.299 & 0.97 & 0.964 \\
& O3D & 7.02 & 7.03 & -0.01 & 0.06 & 0.01 & 0.05 & 0.440 & 0.99 & 0.990 \\
Incisors & Paq & 7.02 & 6.96 & 0.07 & 0.08 & 0.01 & 0.07 & $0.000^{*}$ & 0.99 & 0.987 \\
& MS & 6.23 & 6.29 & -0.06 & 0.20 & 0.04 & 0.15 & 0.093 & 0.91 & 0.909 \\
& O3D & 6.51 & 6.49 & 0.02 & 0.05 & 0.01 & 0.03 & 0.056 & 0.99 & 0.993 \\
& Paq & 6.53 & 6.49 & 0.04 & 0.05 & 0.01 & 0.04 & $0.000^{*}$ & 0.99 & 0.994 \\
& MS & 6.66 & 6.71 & -0.05 & 0.13 & 0.02 & 0.09 & 0.056 & 0.96 & 0.960 \\
\hline
\end{tabular}

*Statistical significance

Table 2: Mean and standard deviation of the results and analysis of variance among the O3d, Caliper (Paq) and MicroScribe (MS) methods

\begin{tabular}{llllll}
\hline Variable & Method & Mean & $D P$ & & $P($ ANOVA $)$ \\
\hline Molars & O3D & 90.81 & 0.53 & A & 0.009 \\
& Paq & 90.83 & 0.54 & A & \\
Premol & MS & 10.22 & 0.63 & $\mathrm{~B}$ & \\
& O3D & 6.43 & 0.34 & $\mathrm{~A}$ & 0.002 \\
& Paq & 6.50 & 0.38 & $\mathrm{~A}$ & \\
& MS & 6.79 & 0.47 & $\mathrm{~B}$ & \\
Canines & O3D & 7.02 & 0.45 & $\mathrm{~B}$ & 0.000 \\
& Paq & 6.99 & 0.47 & $\mathrm{~B}$ & \\
& MS & 6.26 & 0.46 & $\mathrm{~A}$ & \\
& O3D & 6.50 & 0.39 & & 0.155 \\
& Paq & 6.51 & 0.41 & & \\
& MS & 6.69 & 0.44 & & \\
\hline
\end{tabular}

*Statistical significance; Different letters = statistical significance ANOVA: Analysis of variance

hundredths of millimeters, which could be considered clinically irrelevant. The coefficient of precision (CP) demonstrated excellent repeatability of the measurements with the 3 methods, with the widest variations being observed with the MS.

The mean values found for the mesiodistal size of the molars measured with the caliper were identical to those measured with the O3d software but were different from the MS, for which they were $0.39 \mathrm{~mm}$ greater on average for the caliper and $0.41 \mathrm{~mm}$ greater for the O3d application. This finding also occurred for the premolars, with the values obtained being $0.29 \mathrm{~mm}$ less with the caliper and $0.36 \mathrm{~mm}$ less with the O3d application, on average, than with the MS. For the measurements of the size of the canines, the opposite relationship was observed: the values obtained with the caliper and the O3d software were, respectively, $0.73 \mathrm{~mm}$ and $0.76 \mathrm{~mm}$ greater than those obtained using the MS (Table 2).

In Table 3, it is observed that the largest random errors occurred in the measurement of the Bolton anterior analysis and Bolton total when the instrument of measurement was the MS, with values greater than 0.10. In the evaluation of systematic error (p), a significant difference occurred in the measurements carried out with the caliper for the Bolton anterior analysis and for Little's Irregularity Index. The correlation (r) between the first and the second measurements was excellent, and the difference observed was in hundredths of millimeters, which is clinically irrelevant. The $\mathrm{CP}$ demonstrated excellent repeatability of the methods, with the greatest differences being observed with the MS.

The means of the difference and the analysis of variance of the measurements and the distances are shown in Table 4. A significant difference may be observed for the three measuring instruments in the analysis of total Bolton, Bolton anterior, overbite and Little, with the highest values having been obtained using the MS.

\section{DISCUSSION}

Numerous studies have obtained data for diverse analyses carried out on plaster models. Among the existing methods for the analysis of models, we can mention the use of mechanical and digital calipers, video cameras, ${ }^{20}$ computers linked to two-dimensional digitalizers, 3,12 scanners based on three-dimensional digitalizers ${ }^{16,20,21}$ and laser scanners ${ }^{7,10,11,19}$ and mechanical three-dimensional digitalizers MS ${ }^{4,9}$ For this study, the precision, accuracy and reproducibility of the measurements obtained using three instruments of measurement were evaluated: the use of a digital caliper and of MS on plaster models and of applications of the O3d System on digital models.

The evaluation of the measurements of the plaster models and of their digital images was undertaken based on groups of teeth: molars, premolars, canines and incisors, as presented by Zilberman et al. ${ }^{21}$

All groups of teeth presented excellent correlation and discrete intra-examiner errors (Table 1). However, the measurements obtained with the caliper presented stati- 
Table 3: Mean values, difference, standard deviation, standard error of difference, random error (Dahlberg), systematic error ( $p$ ) in $\mathrm{mm}$, correlation $(r)$ and coefficient of precision (CP) for total Bolton, anterior Bolton, Little I.I., overjet (OJ), overbite (OB), upper canine distance (Dcansup), lower canine distance (Dcaninf), upper molar distance (Dmolsp) and lower canine distance (Dmolinf)

\begin{tabular}{|c|c|c|c|c|c|c|c|c|c|c|}
\hline Variable & Method & Mean 1 & Mean 2 & Difference & $D P$ & $E P$ & Dalhberg & $P$ & $r$ & $C P$ \\
\hline \multirow[t]{3}{*}{ Bolton Total } & O3d & 91.93 & 91.97 & -0.03 & 0.64 & 0.12 & 0.45 & 0.787 & 0.95 & 0.949 \\
\hline & Paq & 91.97 & 91.77 & 0.20 & 0.50 & 0.09 & 0.37 & 0.035 & 0.97 & 0.959 \\
\hline & MS & 94.51 & 94.78 & -0.26 & 1.85 & 0.34 & 1.30 & 0.444 & 0.78 & 0.861 \\
\hline \multirow[t]{3}{*}{ Bolton Ante } & O3d & 79.35 & 79.21 & 0.13 & 0.68 & 0.12 & 0.48 & 0.289 & 0.96 & 0.965 \\
\hline & Paq & 79.76 & 79.09 & 0.67 & 0.80 & 0.15 & 0.73 & $0.000^{*}$ & 0.96 & 0.948 \\
\hline & MS & 84.63 & 84.93 & -0.31 & 2.27 & 0.41 & 1.59 & 0.464 & 0.77 & 0.901 \\
\hline \multirow[t]{3}{*}{ Little I.I. } & O3d & 4.20 & 4.25 & -0.05 & 0.74 & 0.13 & 0.51 & 0.708 & 0.94 & 0.935 \\
\hline & Paq & 3.48 & 3.36 & 0.12 & 0.20 & 0.04 & 0.16 & $0.003^{*}$ & 0.99 & 0.990 \\
\hline & MS & 4.40 & 4.39 & 0.01 & 1.40 & 0.26 & 0.97 & 0.961 & 0.68 & 0.800 \\
\hline \multirow[t]{3}{*}{ OJ } & O3d & 3.58 & 3.63 & -0.05 & 0.64 & 0.12 & 0.45 & 0.685 & 0.81 & 0.831 \\
\hline & Paq & 4.03 & 4.00 & 0.02 & 0.29 & 0.05 & 0.20 & 0.687 & 0.98 & 0.980 \\
\hline & MS & 3.42 & 3.56 & -0.15 & 0.53 & 0.10 & 0.39 & 0.144 & 0.85 & 0.949 \\
\hline \multirow[t]{3}{*}{ OB } & O3d & 2.13 & 2.20 & -0.07 & 0.21 & 0.04 & 0.16 & 0.086 & 0.99 & 0.992 \\
\hline & Paq & 2.81 & 2.76 & 0.06 & 0.23 & 0.04 & 0.17 & 0.208 & 1.00 & 0.996 \\
\hline & MS & 4.32 & 4.39 & -0.07 & 0.57 & 0.10 & 0.40 & 0.520 & 0.92 & 0.911 \\
\hline \multirow[t]{3}{*}{ DCansup } & O3d & 34.22 & 34.28 & -0.06 & 0.35 & 0.06 & 0.25 & 0.381 & 0.99 & 0.992 \\
\hline & Paq & 34.36 & 34.32 & 0.04 & 0.14 & 0.03 & 0.10 & 0.151 & 1.00 & 0.998 \\
\hline & MS & 34.49 & 34.46 & 0.03 & 0.33 & 0.06 & 0.23 & 0.623 & 0.99 & 0.590 \\
\hline \multirow[t]{3}{*}{ Dcaninf } & O3d & 26.69 & 26.68 & 0.01 & 0.32 & 0.06 & 0.22 & 0.874 & 0.99 & 0.990 \\
\hline & Paq & 26.51 & 26.48 & 0.03 & 0.15 & 0.03 & 0.10 & 0.264 & 1.00 & 0.997 \\
\hline & MS & 26.45 & 26.56 & -0.12 & 0.35 & 0.06 & 0.26 & 0.078 & 0.98 & 0.559 \\
\hline \multirow[t]{3}{*}{ Dmolsp } & O3d & 52.78 & 52.86 & -0.07 & 0.27 & 0.05 & 0.19 & 0.155 & 1.00 & 0.996 \\
\hline & Paq & 52.54 & 52.52 & 0.02 & 0.10 & 0.02 & 0.07 & 0.238 & 1.00 & 1.000 \\
\hline & MS & 52.83 & 52.83 & 0.00 & 0.41 & 0.07 & 0.28 & 0.990 & 0.99 & 0.902 \\
\hline \multirow[t]{3}{*}{ Dmolinf } & O3d & 47.14 & 46.85 & 0.29 & 0.53 & 0.10 & 0.42 & $0.005^{*}$ & 0.98 & 0.984 \\
\hline & Paq & 45.98 & 45.98 & 0.00 & 0.20 & 0.04 & 0.14 & 0.930 & 1.00 & 0.998 \\
\hline & MS & 46.22 & 46.12 & 0.10 & 0.26 & 0.05 & 0.19 & $0.048^{*}$ & 1.00 & 1.000 \\
\hline
\end{tabular}

*Statistical significance

stically significant systematic errors for the premolars, canines and incisors. These results did not corroborate the study of Zilberman et al, ${ }^{21}$ who reported systematic errors only for the molar group of teeth, when they used the measurement tools of OrthoCAD software.

An intra-examiner variation of the measurements of the central incisor and the first upper molar of the left side, obtained using a digital caliper on plaster models, was also reported by Dalstra and Melsen, ${ }^{2}$ while identical intraexaminer agreement was found, both for plaster models and digital models, in the work of Quimby et al. ${ }^{14}$

The excellent intra-examiner agreement observed in this study may also be proved by the $\mathrm{CP}$, which was greater than 0.95 for the majority of the groups of teeth analyzed (Table 1). According to Asquith et al, ${ }^{1}$ values of the CP greater than 0.80 are generally accepted as being high.

The means of the difference observed in the mesiodistal size of the teeth in this study, between the first and the second measurement, varied between 0.00 and 0.09 $\mathrm{mm}$ (Table 1). These values have no clinical relevance because they are less than the variance that is considered acceptable, which is $0.20 \mathrm{~mm}$, according to Schirmer and Wiltshire, ${ }^{17}$ and $0.30 \mathrm{~mm}$, according to Hirogaki et al. ${ }^{5}$
The measurements obtained by the three instruments (Table 2) proved to be statistically different, with the values obtained by the caliper being identical to those obtained using the O3d software and less than those obtained by the MS. The similarity between the values found when the measurements were carried out by the caliper and using the digital images was also reported by Zilberman et al, ${ }_{1}^{21}$ who evaluated groups of teeth, and by Quimby et $\mathrm{al}_{1}^{14}$ Stevens et $\mathrm{al}^{19}$ and Oliveira et $\mathrm{al}^{11}$ who evaluated the teeth individually. The results of this study did not corroborate those of Dalstra and Melsen, ${ }^{2}$ who found greater values for the sizes of teeth 11 and 16 measured by the caliper, or of Santoro et $\mathrm{al}_{1}{ }^{16}$ who also found greater values for all teeth measured by the caliper.

The results of the linear measurements of the size of the teeth and of the analyses showed excellent correlations, except for the upper canine and lower canine distances when the instrument of measurement was the MS (Table 3). The means of the differences of the measurements for all the instruments, which varied between 0.01 and $0.29 \mathrm{~mm}$, were clinically irrelevant, ${ }^{5,17}$ however.

The comparison of the measurements obtained by the three different methods demonstrated statistically 
Table 4: Means and standard deviations of the distance and analysis of variance among the O3d, caliper (Paq) and MicroScribe (MS) methods

\begin{tabular}{|c|c|c|c|c|c|}
\hline \multicolumn{6}{|c|}{ ANOVA } \\
\hline Variable & Method & Mean & & $D P$ & $p($ ANOVA) \\
\hline \multirow[t]{3}{*}{ BT } & O3D & 91.95 & A & 2.05 & $0.000^{*}$ \\
\hline & Paq & 91.87 & A & 1.79 & \\
\hline & MS & 94.64 & B & 2.63 & \\
\hline \multirow[t]{3}{*}{$\mathrm{Ba}$} & O3D & 79.28 & A & 2.51 & $0.000^{*}$ \\
\hline & Paq & 79.42 & A & 2.58 & \\
\hline & MS & 84.78 & B & 3.10 & \\
\hline \multirow[t]{3}{*}{ Little } & O3D & 4.23 & A & 1.83 & $0.049^{*}$ \\
\hline & Paq & 3.42 & A & 1.40 & \\
\hline & MS & 4.39 & B & 1.61 & \\
\hline \multirow[t]{3}{*}{ Oj } & O3D & 3.60 & & 0.96 & 0.177 \\
\hline & Paq & 4.01 & & 1.42 & \\
\hline & MS & 3.49 & & 0.95 & \\
\hline \multirow[t]{3}{*}{$\mathrm{Ob}$} & O3D & 2.17 & A & 1.68 & $0.000^{*}$ \\
\hline & Paq & 2.79 & A & 2.67 & \\
\hline & MS & 4.36 & B & 1.40 & \\
\hline \multirow[t]{3}{*}{ DCanSup } & O3D & 34.25 & & 2.67 & 0.944 \\
\hline & Paq & 34.34 & & 2.57 & \\
\hline & MS & 34.48 & & 2.58 & \\
\hline \multirow[t]{3}{*}{ Dcanlnf } & O3D & 26.69 & & 2.22 & 0.920 \\
\hline & Paq & 26.49 & & 1.96 & \\
\hline & MS & 26.51 & & 1.98 & \\
\hline \multirow[t]{3}{*}{ DmolSup } & O3D & 52.82 & & 3.22 & 0.923 \\
\hline & Paq & 52.53 & & 3.33 & \\
\hline & MS & 52.83 & & 3.28 & \\
\hline \multirow[t]{3}{*}{ Dmollnf } & O3D & 46.99 & & 2.96 & 0.378 \\
\hline & Paq & 45.98 & & 2.97 & \\
\hline & MS & 46.17 & & 3.01 & \\
\hline
\end{tabular}

*Statistical difference

significant differences for total Bolton, Bolton anterior, Little's Irregularity Index and overbite (Table 4). In the analysis of total Bolton and Bolton anterior in this study, the values obtained were identical for the plaster models and for the digital images but less than those for the MS. Similarity between the measurements obtained with plaster and digital models was also reported by Mullen et $\mathrm{al}^{10}$ and Tomasseti et $\mathrm{al}^{20}{ }^{20}$ who analyzed total Bolton, and Stevens et $\mathrm{al}^{19}$ and Paredes et $\mathrm{al}_{1}{ }^{12}$ who analyzed total Bolton and Bolton anterior.

Little's Irregularity Index was identical when obtained by the caliper and O3d but was different when obtained by the MS, agreeing with Martins, ${ }^{9}$ who found underestimated results for this index in his study.

The MS was the instrument that presented the greatest variation in the measurements and analyses, probably due to the active point of the instrument being conic and of a greater dimension than the points of reference, which hindered its correct positioning. According to the manufacturers of the MS, the device error is $0.23 \mathrm{~mm}{ }^{9}$

The measurements obtained from the digital models were precise and reproducible; however, some diffi- culties were encountered in the measurement of the digital models, such as difficulty in recording the data from the models using the O3d program and the lack of discrimination in the dental numeration. In relation to the image, there was difficulty in distinguishing the mesiodistal diameter of the anterior teeth when there was no crowding and in distinguishing the tips of the molar cusps, because some teeth did not have clear contours. These observations should be corrected in the next version of the O3d system.

\section{CONCLUSION}

1. The digital model of the O3d proved to be accurate and precise and could be considered a reliable device for clinical and scientific use by orthodontists.

2. The MS proved to be accurate for the measurements carried out on the plaster models, but it presented greater variability and underestimation of the measurements analyzed.

3. The caliper and the O3d presented identical performance in obtaining measurements and analyses.

\section{REFERENCES}

1. Asquith J, Gillgrass T, Mossey P. Three-dimensional imaging of orthodontic models: a pilot study. Eur J Orthod 2007; 29(5):517-522.

2. Dalstra M, Melsen B. From alginate impressions to digital virtual models: accuracy and reproducibility. J Orthod 2009; 36(1):36-41.

3. Gracco A, Buranello M, Cozzani M, Siciliani G. Digital and plaster models: a comparison of measurements and times. Prog Orthod 2007;8(2):252-259.

4. Hayasaki H, Martins RP, Gandini LG, Saitoh I, Nonaka K. A new way of analyzing occlusion 3 dimensionally. Am J Orthod Dentofacial Orthop 2005 Jul;128(1):128-132.

5. Hirogaki, Y, Sohmura T, Satoh H, Takahashi J, Takada K. Complete 3-D reconstruction of dental cast shape using perceptual grouping. IEEE Trans Med Imaging 2001;20:1093-1101.

6. Houston WJ. The analysis of errors in orthodontic measurements. Am J Orthod 1983;83(5):382-390.

7. Keating AP, Knox J, Bibb R, Zhurov AI. A comparison of plaster, digital and reconstructed study model accuracy. J Ortho 2008;35(3):191-201.

8. Little RM. The irregularity index: a quantitative score of mandibular anterior alignment. Am J Orthod 1975;68(5): 554-563.

9. Martins RP. Análise tridimensional da oclusão normal na população branca brasileira [tese de mestrado]. Araraquara: Faculdade de Odontologia da UNESP; 2004.

10. Mullen SR, Martin CA, Ngan P, Gladwin M. Accuracy of space analysis with emodels and plaster models. Am J Orthod Dentofacial Orthop 2007;132(3):346-352.

11. Oliveira, et al. Confiabilidade do uso de modelos digitais tridimensionais como exame auxiliar ao diagnóstico ortodôntico: um estudo piloto. 2007;12(1):84-93.

12. Paredes V, Gandia JL, Cibrian R. Determination of Bolton tooth-size ratios by digitization, and comparison with the traditional method. Eur J Orthod 2006 Apr;28(2):120-125. 
13. Paredes V, Gandia JL, Cibrian R. Digital diagnosis records in orthodontics. An overview. Med Oral Patol Oral Cir Bucal 2006 Jan;11(1):E88-E93.

14. Quimby ML, Vig KW, Rashid RG, Firestone AR. The accuracy and reliability of measurements made on computer-based digital models. Angle Orthod 2004 Jun;74(3):298-303.

15. Redmond WR. Digital models: a new diagnostic tool. J Clin Orthod 2001 Jun;35(6):386-387.

16. Santoro M, Galkin S, Teredesai M, Nicolay OF, Cangialosi TJ. Comparison of measurements made on digital and plaster models. Am JOrthod Dentofacial Orthop 2003 Jul;124(1):101-105.

17. Schirmer UR, Wiltshire WA. Manual and computer-aided space analysis: a comparative study. Am J Orthod Dentofac Orthop 1997;112(6):676-680.

18. Sohmura DT, Kojima T, Wakabayashi K, Takahashi J. Use of an ultrahigh-speed scanner for constructing three-dimensional shapes of dentition and occlusion. J Prosth Dent 2000 Sep; 84(3):345-352.
19. Stevens DR, Flores-Mir C, Nebbe B, Raboud DW, Heo G, Major PW. Validity, reliability, and reproducibility of plaster vs digital study models: comparison of peer assessment rating and Bolton analysis and their constituent measurements. Am J Orthod Dentofacial Orthop 2006 Jun;129(6): 794-803.

20. Tomassetti JJ, et al. A comparison of 3 computerized Bolton tooth-size analyses with a commonly used method. Angle Orthod 2001 Sept;71(5):351-357.

21. Zilberman O, Huggare JA, Parikakis KA. Evaluation of the validity of tooth size and arch width measurements using conventional and three-dimensional virtual orthodontic models. Angle Orthod 2003 Jun;73(3):301-306.

22. Whetten JL, Williamson PC, Heo G, Varnhagen C, Major PW. Variations in orthodontic treatment planning decisions of Class II patients between virtual 3-dimensional models and traditional plaster study models. Am J Orthod Dentofacial Orthop 2006 Oct;130(4):485-491. 